\title{
Glycerophosphorylcholine and Phosphorylcholine Measurement
}

National Cancer Institute

\section{Source}

National Cancer Institute. Glycerophosphorylcholine and Phosphorylcholine

Measurement. NCI Thesaurus. Code C158261.

The determination of the amount of glycerophosphorylcholine and phosphorylcholine present in a sample. 